\title{
DO TRABALHO PARA A EJA: PRÁTICAS SOCIAIS E FORMAÇÃO DE PROFESSORES NO/DO/PARA O CAMPO
}

Verônica Klepka ${ }^{1}$

\section{RESUMO}

A atuação na Educação de Jovens e Adultos do campo pressupõe considerar os alunos que chegam à EJA como trabalhadores que lutam por uma vida digna, e carregam inúmeras experiências produzindo conhecimentos em cada prática social vivenciada. Deste modo, o trabalho no/do campo é uma temática fértil para ser considerada na formação de professores para a EJA. Neste artigo, assumimos as reflexões de Miguel Arroyo como referencial teórico para a formação de professores para a EJA e apresentamos a experiência pedagógica frente à disciplina de EJA em um curso de Licenciatura em Educação do Campo no Estado de Minas Gerais com o propósito de discutir a potencialidade do trabalho no/do campo, enquanto prática social para a prática pedagógica de futuros professores da EJA do campo. As informações provêm de 52 trabalhos finais da disciplina ao longo dos anos de 2019 e 2020. Podemos observar um grande número de práticas sociais emergentes dos contextos dos licenciandos, predominantemente do campo, com destaque para o cultivo e/ou produção de derivados da mandioca. Percebemos ainda a existência de conhecimentos matemáticos e científicos nestas práticas o que possibilitou aos licenciandos a proposição de aulas para contextos de EJA, utilizando-se da potencialidade da temática para um diálogo entre a atividade exercida pelos trabalhadores da EJA e os conhecimentos escolares. $\mathrm{O}$ trabalho no/do campo passa a ser assumido por estes licenciandos como locais de produção de conhecimentos, prática social, a qual seu

\footnotetext{
${ }^{1}$ Doutora em Educação para Ciência e a Matemática (UEM). Professora da Universidade Federal do Triângulo Mineiro (UFTM) no curso de Licenciatura em Educação do Campo (LECampo) e no Programa de Pós-Graduação em Educação em Ciências e Matemática (PPGECM). ORCID: https://orcid.org/0000-0002-9937-9852.

E-mail: veronica.klepka@uftm.edu.br
} 
modo de viver e sobreviver são aspectos estreitamente vinculados a um projeto de campo emancipatório.

Palavras-chave: Trabalho enquanto Prática Social. Formação de Professores para a EJA. Educação no/do Campo.

\section{FROM WORK TO EJA: SOCIAL PRACTICES AND TEACHER TRAINING IN/OF/FOR RURAL EDUCATION}

\section{ABSTRACT}

The acting in the Youth and Adult Education presupposes considering the students who come to EJA as workers who fight for a dignified life and carry countless experiences producing knowledge in each social practice experienced. Thus, peasant work is a fertile topic to be considered in the training of teachers for EJA. In this article, we take Miguel Arroyo's reflections as a theoretical framework for teacher education for EJA and present the pedagogical experience facing the EJA discipline in a degree course in Rural Education in the State of Minas Gerais with the purpose of discussing the potential of rural work in/in, as a social practice for the pedagogical practice of future teachers of the EJA of the rural education. The information comes from the 52 course's final works throughout the years 2019 and 2020. We can observe a large number of social practices emerging from the contexts of the undergraduates, predominantly from the countryside, with an emphasis on the cultivation and/or production of cassava derivatives. We also noticed the existence of mathematical and scientific knowledge in these practices, which enabled the undergraduates to propose classes for EJA contexts, using the potential of the theme for a dialogue between the activity performed by EJA workers and school knowledge. Rurak Work in/the is assumed by these graduates as places of production of knowledge, a social practice to which their way of living and surviving are aspects closely linked to an emancipatory project.

Keywords: Work as a Social Practice. Teacher Training for EJA. Rural Education. 


\section{DEL TRABAJO A EJA: PRÁCTICAS SOCIALES Y FORMACIÓN DE PROFESORES EM/DE/PARA EL CAMPO}

\section{RESUMEN}

La actuación en la Educación de Jóvenes y adultos en el campo presupone considerar a los estudiantes que llegan a EJA como trabajadores que luchan por una vida digna y llevan innumerables experiencias productoras de conocimiento en cada práctica social vivida. Así, el trabajo en / en el campo es un tema fértil a ser considerado en la formación de docentes para EJA. En este artículo, tomamos las reflexiones de Miguel Arroyo como marco teórico para la formación de la maestria para EJA y presentamos la experiencia pedagógica que enfrenta la disciplina EJA en un curso de Grado en Educación Rural en el Estado de Minas Gerais con el propósito de discutir el potencial del trabajo en / en el campo, como una práctica social para la práctica pedagógica de futuros profesores de la EJA del campo. La información proviene de los trabajos finales de la disciplina durante los años 2019 y 2020. Podemos observar una gran cantidad de prácticas sociales que emergen de los contextos de los estudiantes, predominantemente del campo, con énfasis en el cultivo y / o producción de derivados de la yuca. También notamos la existencia de conocimientos matemáticos y científicos en estas prácticas, lo que permitió a los estudiantes de pregrado proponer clases para contextos EJA, utilizando el potencial de la temática para un diálogo entre la actividad realizada por los trabajadores de EJA y el conocimiento escolar. El trabajo en / en el campo es asumido por estos egresados como lugares de producción de conocimiento, una práctica social para la cual su forma de vivir y sobrevivir son aspectos muy ligados a un proyecto de campo emancipador.

Palabras clave: Trabajo como Práctica Social. Formación de Professores para EJA. Educación de Campo. 


\section{INTRODUÇÃO}

No Brasil, a Educação de Jovens e Adultos do campo resulta da luta e articulação de movimentos sociais e sindicais como principais agentes de mobilização de parcerias junto à programas e projetos, a exemplo do Programa Nacional de Educação na Reforma Agrária, O PRONERA (MOLINA; ANTUNES-ROCHA, 2014). Nestas parcerias, os processos educativos dos jovens e adultos são pensados para o público do campo, ou seja, se desenvolvem rompendo com: conteúdos escolares esvaziados e sem sentido, burocracias, interesses antagônicos àqueles que orientam a Educação do Campo e horários que impossibilitam o acesso e a permanência dos homens e mulheres do campo. Numa lógica contrária, esta EJA vislumbra aprendizados que possam contribuir com a transformação da realidade. Um exemplo disso é a EJA realizada no seio dos movimentos sociais, como o Movimento dos Trabalhadores Rurais Sem Terra, o qual contribuiu sobremaneira para se pensar na educação como indissociável das questões políticas que cercam os sujeitos, dando aos processos educativos intencionalidade. Entretanto, parcerias por vezes descontinuadas, também apresentam contradições como educadores sem relação com o campo e com pouca ou nenhuma formação para esta modalidade de educação, o que ressalta a precarização com que a EJA é tratada no país, principalmente pensando em contextos campesinos (FREITAS; SILVA, 2016).

Arroyo (2006) elenca uma série de fatores que tem historicamente reforçado esta precarização: "professor generalista que poderá dar aula no diurno, a criança e adolescentes, e no noturno, a jovens e adultos" (p.21); desconhecedores dos sujeitos que compõem à EJA, bem como de suas trajetórias de vida, de trabalho e de luta; currículos engessados, conteudistas e sem qualquer relação com a visão sociológica e histórica sobre os jovens e adultos EJA; etc. $\mathrm{Na}$ EJA em contextos do campo estes fatores são igualmente preocupantes e somam-se a outros mais.

A EJA no campo pode ser vista a partir de duas perspectivas. De um lado, a partir de um campo no qual a educação é pensada e realizada a partir da reprodução de um ensino regular, urbano, ou 
seja, a partir de um projeto capitalista na qual a formação de jovens e adultos é voltada para a mão de obra (FREITAS; SILVA, 2016). Não é à toa que a percepção que muitas vezes se tem da EJA, enquanto modalidade de educação, mesmo pelos próprios sujeitos que dela participam, estudantes do campo e da cidade, seja como meio pelo qual possam se profissionalizar e conquistar o diploma. Visão esta, muitas vezes, reforçada pela escola (FERREIRA; AUTOR, 2019).

Do outro lado, a EJA voltada a um campo na perspectiva do projeto do agricultor familiar camponês, tendo a terra como identidade, território de vida e produção de conhecimentos. Esta EJA demanda por experiências educacionais que sejam condizentes com suas necessidades, ao mesmo tempo em que, dê sentido ao modo de viver e produzir destes povos, ou seja, assumir os jovens e adultos que chegam à EJA enquanto trabalhadores e trabalhadoras, sendo esta sua identidade, uma condição sociopolítica. Trata-se de assumir o "trabalho como referente ético-político-pedagógico" (ARROYO, 2017, p. 43).

Ver os jovens-adultos como trabalhadores exige não vê-los apenas como estudantes em percursos escolares truncados a serem supridos. Nem sequer vê-los como estudantes que trabalham. Ser trabalhador não é um acidente a mais na sua condição de estudantes. Como ser pobres e lutar pela sobrevivência em trabalhos formais ou informais não é um acidente dos jovens-adultos estudantes na EJA (ARROYO, 2009, p. 16).

Diante da necessidade latente de uma formação de professores que considere o trabalho como referência pedagógica para a EJA do campo, enxergamos no Curso de Licenciatura em Educação do Campo o local privilegiado para este debate. Tendo como licenciandos os próprios trabalhadores que vivem e sobrevivem da terra, sujeitos de direitos e produtores de uma rica e vasta gama de culturas, a EJA pode ser pensada e planejada a partir do campo e para o campo.

Neste sentido, este artigo resulta de reflexões teóricas e pedagógicas proporcionadas pela experiência, especificamente, nos dois últimos anos como docente da disciplina de Educação de Jovens 
e Adultos no contexto do curso de Licenciatura em Educação do Campo (LECampo), da Universidade Federal do Triângulo Mineiro (UFTM). O objetivo consiste em discutir a potencialidade do trabalho no/do campo, enquanto prática social, como matriz formativa para a prática pedagógica de futuros professores e professoras de Jovens e Adultos do campo.

A expressão apontada no título "Do trabalho para a EJA" carrega, intencionalmente, por um lado, as reflexões de Arroyo (2017) acerca dos itinerários por justiça que os homens e mulheres cotidianamente enfrentam para acessar e permanecer na educação. Por outro lado, propõe o trabalho, enquanto prática social, como matriz formativa para se pensar na Educação do Campo, especificamente, na formação de professores de jovens e adultos no/do e para o projeto emancipatório de campo em nossa sociedade.

\section{A EDUCAÇÃO DE JOVENS E ADULTOS NO/DO/PARA O CAMPO}

Se no contexto urbano a demanda de jovens e adultos por escolarização é alta, no campo, esta situação torna-se ainda mais agravante. De acordo com a pesquisa de amostragem do Instituto Brasileiro de Geografia e Estatística (IBGE) que abrangeu cerca de 212 mil pessoas no primeiro trimestre de $2021,33,5 \%$ da população indicou como grau de instrução o Ensino Fundamental incompleto; 6,7\% disseram possuir o Ensino Médio incompleto e, 7,2\% da população, indicou não ter instrução ou ter frequentado a escola por menos de um ano. A pesquisa não discrimina o percentual dos domicílios rurais amostrados, entretanto, dados do Censo Escolar de 2014 do Instituto Nacional de Estudos e Pesquisas Educacionais Anísio Teixeira (INEP) indicam que oito milhões de pessoas em idade escolar vivem no campo. Na zona rural o índice de analfabetismo chega a $20 \%$ e a taxa de abandono escolar é quase $70 \%$, maior do que na zona urbana (BRASIL, 2021). Ainda de acordo com o INEP, $33,9 \%$ das escolas brasileiras encontram-se localizadas na zona rural. O ensino médio é oferecido em apenas $10,2 \%$ das escolas do campo, 
o que implica no deslocamento dos estudantes para a cidade ou o abandono escolar (INEP, 2017).

Quando olhamos para os índices percebemos que, de modo geral, o número de matrículas na EJA diminuiu 7,7\% no último ano, chegando a 3,2 milhões em 2019 (INEP, 2020). No período de 20082016 também houve uma queda de $26,8 \%$ o número de escolas que oferecem a modalidade de Educação de Jovens e Adultos no Brasil (INEP, 2017).

Números de professores e salas de aula reduzidos, falta de energia elétrica, esgoto e abastecimento de água são algumas das situações enfrentadas pelas escolas do campo. Com o fechamento de muitas destas escolas, ocorrido na última década, a EJA em contextos do campo tornou-se ainda mais ameaçada. Somada à esta realidade, está a necessidade por uma formação de professores adequada ao perfil dos estudantes do campo e às demandas dos trabalhadores e trabalhadoras do campo quanto à educação. Molina e AntunesRocha (2014, p.222) ressaltam que entre os desafios está o

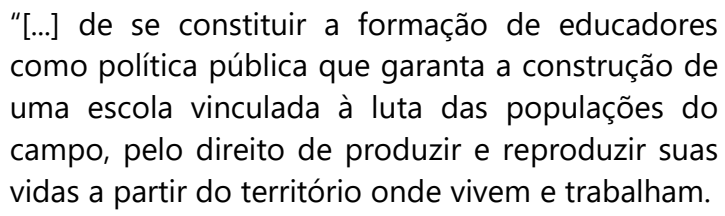

Pensar no trabalho no/do campo como matriz formativa para a EJA pressupõe pensar nos dilemas da educação do trabalhador que historicamente permearam a sociedade brasileira e que opuseram trabalho e conhecimento, relegando a educação dos trabalhadores à uma mera instrução para o mercado de trabalho em detrimento de uma educação enquanto direito e de modo emancipatório. Neste sentido, a instrução e a educação do trabalhador são faces opostas de projetos distintos de sociedade (FRIGOTTO, 2012a).

O trabalho, no sentido adotado por este artigo, é entendido como "[...] relação social fundamental, manifestação da vida, isto é, atividade do homem na apropriação e transformação do mundo, da realidade em si mesma [...]" (FRIGOTTO, 2012b). O trabalho é uma dentre muitas práticas sociais. 
Práticas sociais decorrem de e geram interações entre os indivíduos e entre eles e os ambientes natural, social e cultural em que vivem. Desenvolvem-se no interior de grupos, de instituições, com o propósito de produzir bens, transmitir valores, significados, ensinar a viver e a controlar o viver; enfim, manter a sobrevivência material e simbólica das sociedades humanas (OLIVEIRA et al, 2014, p.33).

É preciso ressaltar que o conceito de prática social é amplo e não contempla apenas o trabalho. Desse modo, todo trabalho é prática social, mas nem toda prática social é trabalho. Entendidos como prática social, o trabalho ou as atividades relacionadas ao trabalho, carregam aprendizagens e possibilidades de construção de visões críticas em relação a sua produção na sociedade. Quando não alienado, permite a conquista da autonomia e o rompimento com práticas opressoras e discriminatórias. Assim, as práticas sociais também são produtoras de identidades, realizadas por "[...] pessoas com diferentes percepções e conhecimentos, em diferentes processos de trabalho e lazer, em diferentes espaços, escolares e não escolares." (OLIVEIRA et al, 2014, p.35).

Ao entender o trabalho enquanto prática social é preciso considerar que ele está imerso em relações de força, de poder e de violência ao mesmo tempo em que não se reduz à produção de subsistência. O trabalho assume todas estas faces e, simultaneamente, carrega a produção e reprodução viva e dinâmica da sociedade, das expressões culturais, artísticas, entre tantas outras dimensões, aponta Frigotto (2012b).

A formação de professores para a EJA do campo deve, portanto, ter como premissa a proposição de práticas educativas que dialoguem com a prática social dos sujeitos camponeses, valorizando as identidades culturais dos educandos assim como seus saberes. Para Arroyo (2006), o perfil do educador de jovens e adultos ainda está em construção, mas discute a necessidade de que este educador (a) não pode ser generalista, submisso aos processos reguladores da escola. Os povos do campo demandam outros educadores. Educadores plurais, que reconheçam as especificidades da EJA e sua história, que reconheçam os sujeitos que chegam à EJA como sujeitos 
de direitos, que tiveram sua vida marcada por opressões e interdições. Que se tratam de jovens e adultos trabalhadores que carregam uma ampla gama de experiências e expectativas e para os quais os conteúdos, pedagogias e tempos não podem, e não devem, ser os mesmos do ensino regular. Os alunos trabalhadores carregam processos educativos com potencial de concretização em matriz formativa para a EJA no/do/para o campo. É nesta perspectiva que a LECampo/UFTM tem trabalhado a formação de professores para os jovens e adultos do campo.

\section{O CONTEXTO DE PRODUÇÃO DAS INFORMAÇÕES}

As informações que serão apresentadas e discutidas neste artigo referem-se à uma amostra de trabalhos de prática como componente curricular (PCC), resultantes da atividade final da disciplina de EJA, sob a responsabilidade da autora durante os anos de 2019 e 2020 no curso de Licenciatura em Educação do Campo da Universidade Federal do Triângulo Mineiro.

O curso de Licenciatura em Educação do Campo da UFTM é um dos quarenta e dois cursos criados com $O$ Edital SESU/SETEC/SECADI $n^{\circ}$ 02/2012 no Brasil. Na LECampo/UFTM, contamos com a formação de professores nas áreas do conhecimento Matemática e Ciências da Natureza. Nossos estudantes são oriundos de cinco principais regiões brasileiras: Norte e Noroeste de Minas Gerais, Triângulo Mineiro, Interior de São Paulo e Sul da Bahia. O curso adota a Pedagogia da Alternância, ou seja, momentos para o estabelecimento de relações entre diferentes tempos e espaços, o da universidade e o da comunidade, o tempo de produzir e o tempo de existir, o que aprender e o de aplicar. Trata-se de uma "[...] estratégia de escolarização, que possibilita aos jovens ((e adultos)) que vivem no campo conjugar a formação escolar com as atividades e tarefas na unidade produtiva familiar, sem desvincularse da família e da cultura do meio rural" (SILVA, 2012, p. 170). Este alternar permite aos sujeitos maiores percepções e reflexões sobre a realidade vivida, tornando as questões que os afligem como objetos de sua formação, complementa Silva (2012). 
A disciplina Educação de Jovens e Adultos (EJA) é oferecida ao primeiro período do curso, chamado ciclo comum, quando ocorre a chegada da turma ingressante na Licenciatura em Educação do Campo da UFTM. A escolha pela área do conhecimento a ser cursada (Matemática ou Ciências da Natureza) ocorre apenas no terceiro período e, quando formado, o profissional poderá atuar, por exemplo, em contextos da Educação de Jovens e Adultos nos níveis da Educação Básica: Ensino Fundamental II e/ou Ensino Médio.

A componente curricular EJA, na LECampo/UFTM, matriz de 2018.2, compõe-se de um total de 45 horas/aula, distribuídas em 15 horas teóricas, 15 horas práticas e 15 horas de prática como componente curricular (PCC). A ementa trabalhada na disciplina compreende os pressupostos históricos e teóricos da Educação de Jovens e Adultos e as possibilidades e limites das propostas de alfabetização de jovens e adultos no Brasil; o papel do educador na Educação de Jovens e Adultos e os saberes indispensáveis à sua prática; objetivos, conteúdos, metodologias, materiais didáticos e avaliação na Educação de Jovens e Adultos; projetos interdisciplinares para o ensino-aprendizagem na EJA; a heterogeneidade do contexto atual da EJA no Brasil e a EJA na educação de trabalhadores do campo (UFTM, 2019).

Nas duas últimas ofertas da EJA na LECampo/UFTM (2019.2 e 2020.2), já aplicando a matriz reformulada (2018.2), conforme ementa descrita anteriormente, o olhar da docente concentrou-se em dar concretude às reflexões trazidas, principalmente, por Miguel Arroyo $(2006,2012,2014,2017)$ para a formação de professores de Jovens e Adultos. Assim, o trabalho passou a ser determinante para o planejamento e execução das reflexões realizadas na disciplina, conforme conteúdo programático descrito no Quadro 1 a seguir:

Quadro 1 - Conteúdo programático desenvolvido na disciplina EJA da LECampo/ UFTM ao longo dos semestres 2019.2 e 2020.2

- História da EJA no Brasil, seus avanços e retrocessos;

- Cenário atual da EJA no Brasil;

- LDB nº 9.394/96: o que dispõe sobre a EJA; 
- Processos que legitimam e constituem historicamente as políticas públicas da EJA;

- Especificidades dos estudantes da EJA;

- Papel dos educadores e da escola nessa modalidade de educação;

- Metodologias e materiais didáticos para EJA;

- A negação histórica aos bens culturais no Brasil;

- Os principais processos e sujeitos de desigualdade no país;

- Diferenças entre o aprendizado do adulto e da criança;

- O método de alfabetização Paulo Freire;

- A existência da relação opressor-oprimido em nosso meio;

- As práticas de desigualdade exercidas pelos processos educativos;

- O trabalho como prática social: de opressão e de emancipação;

- Práticas sociais locais, conhecimentos matemáticos e científicos e sua articulação em contextos EJA;

- Propostas para a EJA considerando seus sujeitos, contextos e necessidades dos alunos trabalhadores.

Fonte: Da autora (2021).

Como pode ser observado, a disciplina de EJA na LECampo/UFTM culmina na proposição de reflexões sobre práticas sociais locais, com vistas a exercitar o olhar dos futuros professores de matemática e ciências para os conhecimentos presentes nelas, propondo sua articulação em contextos de Educação de Jovens e Adultos. Tal propósito é concretizado na atividade de PCC, executada em etapas que perpassam: i) a identificação, no contexto do estudante, de uma prática social comumente realizada e que tenha relação com algum tipo de trabalho; ii) a descrição da prática (o que ela é, quem ou quais pessoas a realiza, como é realizada, quando é exercida, onde acontece, para que serve, em que épocas é mais frequente, quais processos e produtos envolvem, etc.); iii) a identificação dos conhecimentos matemáticos e científicos contidos na prática local e a descrição de quando eles aparecem e em quais processos e etapas do processo eles aparecem); iv) na descrição de como (de que maneira) esses conhecimentos matemáticos e de ciências são utilizados/ aplicados na prática social destacada e, por fim, v) na proposição de uma aula que dialogue a prática social, os 
conhecimentos dos sujeitos que a produzem com os conhecimentos escolares matemáticos e de ciências que aparecem na prática social relacionada ao trabalho no/do campo.

Neste artigo, daremos ênfase a experiência de PCC, apresentando as práticas sociais que emergiram no contexto destes alunos, futuros professores da EJA para o campo, os conhecimentos que carregam e as propostas advindas de suas atividades finais na disciplina. Nosso propósito é discutir a potencialidade do trabalho no/do campo, enquanto prática social, como matriz formativa para a prática pedagógica de futuros professores EJA.

\section{ANÁLISES E DISCUSSÕES}

\section{As práticas sociais locais relacionadas ao trabalho}

No Quadro 2, a seguir, foram sistematizadas as práticas sociais que emergiram dos 52 trabalhos de PCC desenvolvidos pelos licenciandos em Educação do Campo, primeiro período, na LECampo/UFTM como atividade final da disciplina de Educação de Jovens e Adultos ao longo dos semestres 2019.2 e 2020.2, sob a responsabilidade da autora deste artigo. Os licenciandos foram identificados apenas pela legenda " $\mathrm{L}$ ".

Quadro 2 - Práticas sociais locais que emergiram na proposta de PCC desenvolvida pelos licenciandos em Educação do Campo nas turmas 2019.2 e 2020.2 .

\begin{tabular}{|c|c|c|c|c|}
\hline $\begin{array}{c}\text { Turma/ } \\
\text { Ano }\end{array}$ & $\begin{array}{c}\text { Licenciando } \\
\text { (a) }\end{array}$ & Prática Social & $\begin{array}{c}\text { Contexto do (a) } \\
\text { Licenciando (a) }\end{array}$ & $\begin{array}{c}\text { Contexto } \\
\text { da Prática }\end{array}$ \\
\hline & L1 & Crochê & Uberaba-MG & Urbano \\
\cline { 2 - 5 } & L2 & Doces Caseiros & $\begin{array}{c}\text { Zona Rural - } \\
\text { Campo Florido - } \\
\text { MG }\end{array}$ & Camponês \\
\cline { 2 - 6 } & L3 & Cultivo de Mandioca & $\begin{array}{c}\text { Comunidade } \\
\text { Terra Quebrada } \\
\text { Rio Pardo de } \\
\text { Minas -MG }\end{array}$ & Camponês \\
\cline { 2 - 6 } & L4 & Produção do Polvilho & $\begin{array}{c}\text { Comunidade } \\
\text { Rocinha }\end{array}$ & Camponês \\
\hline
\end{tabular}




\begin{tabular}{|c|c|c|c|c|}
\hline \multirow{14}{*}{2019.2} & & & $\begin{array}{l}\text { Rio Pardo de } \\
\text { Minas - MG }\end{array}$ & \\
\hline & L5 & $\begin{array}{c}\text { Produção da Cachaça } \\
\text { Artesanal }\end{array}$ & $\begin{array}{l}\text { Comunidade } \\
\text { Jardim } \\
\text { Rio Pardo de } \\
\text { Minas -MG }\end{array}$ & Camponês \\
\hline & L6 & $\begin{array}{c}\text { Cerca de Arame (liso e } \\
\text { farpado) }\end{array}$ & $\begin{array}{c}\text { Zona Rural -Santa } \\
\text { Fé -MG }\end{array}$ & Camponês \\
\hline & L7 & Produção da Rapadura & $\begin{array}{l}\text { Comunidade } \\
\text { Riacho Dantas } \\
\text { Rio Pardo de } \\
\text { Minas -MG }\end{array}$ & Camponês \\
\hline & L8 & Produção da Rapadura & $\begin{array}{c}\text { Assentamento } \\
\text { P.A. Porto do } \\
\text { Saco- Natalândia } \\
\text { - MG }\end{array}$ & Camponês \\
\hline & L9 & Cavalgada & $\begin{array}{c}\text { Zona Rural } \\
\text { Riachinho -MG }\end{array}$ & Camponês \\
\hline & L10 & Plantio do Feijão & $\begin{array}{l}\text { Fazenda Santa } \\
\text { Maria } \\
\text { Rio Pardo de } \\
\text { Minas -MG }\end{array}$ & Camponês \\
\hline & L11 & $\begin{array}{l}\text { Produção Artesanal da } \\
\text { Farinha de Mandioca }\end{array}$ & $\begin{array}{c}\text { Comunidade } \\
\text { Riacho Dantas } \\
\text { Rio Pardo de } \\
\text { Minas -MG } \\
\end{array}$ & Camponês \\
\hline & L12 & Cultivo de Mandioca & $\begin{array}{l}\text { Comunidade } \\
\text { Aurora } \\
\text { Rio Pardo de } \\
\text { Minas -MG } \\
\end{array}$ & Camponês \\
\hline & L13 & Produção do Polvilho & $\begin{array}{l}\text { Comunidade de } \\
\text { Jacu } \\
\text { Rio Pardo de } \\
\text { Minas -MG }\end{array}$ & Camponês \\
\hline & L14 & Café Sombreado & $\begin{array}{c}\text { Comunidade } \\
\text { Vereda Funda } \\
\text { Rio Pardo de } \\
\text { Minas -MG }\end{array}$ & Camponês \\
\hline & L15 & Brincadeiras & Uberaba-MG & Urbano \\
\hline & L16 & Cultivo de Mandioca & $\begin{array}{l}\text { Comunidade } \\
\text { Jardim } \\
\text { Rio Pardo de } \\
\text { Minas -MG }\end{array}$ & Camponês \\
\hline & L17 & Produção da Goma & $\begin{array}{l}\text { Comunidade } \\
\text { Rocinha } \\
\text { Rio Pardo de } \\
\text { Minas - MG }\end{array}$ & Camponês \\
\hline
\end{tabular}




\begin{tabular}{|c|c|c|c|c|}
\hline & L18 & Projeto Dandara2 & $\begin{array}{l}\text { São José dos } \\
\text { Campos -MG }\end{array}$ & Urbano \\
\hline & L19 & $\begin{array}{c}\text { Produção da Cachaça } \\
\text { Artesanal }\end{array}$ & $\begin{array}{l}\text { Comunidade } \\
\text { Mestiça } \\
\text { Rio Pardo de } \\
\text { Minas -MG }\end{array}$ & Camponês \\
\hline & L20 & Produção do Polvilho & $\begin{array}{c}\text { Comunidade } \\
\text { Monte Alegre II - } \\
\text { Rio Pardo de } \\
\text { Minas -MG }\end{array}$ & Camponês \\
\hline & L21 & Produção do Polvilho & $\begin{array}{c}\text { Comunidade Tatu } \\
\text { Rio Pardo de } \\
\text { Minas -MG }\end{array}$ & Camponês \\
\hline \multirow{11}{*}{2020.2} & L22 & Receita Mineira & Uberaba-MG & Urbano \\
\hline & L23 & Produção de feijão & $\begin{array}{l}\text { Assentamento } \\
\text { São Francisco II - } \\
\text { São Francisco - } \\
\text { MG }\end{array}$ & Camponês \\
\hline & L24 & $\begin{array}{l}\text { Plantio de mandioca } \\
\text { (Goma e Farinha) }\end{array}$ & $\begin{array}{c}\text { Comunidade } \\
\text { Catanduva - } \\
\text { Vargem Grande } \\
\text { do Rio Pardo -MG }\end{array}$ & Camponês \\
\hline & L25 & Solda & Unaí-MG & Urbano \\
\hline & L26 & Goma e Farinha & $\begin{array}{l}\text { Comunidade } \\
\text { Sobrado } \\
\text { Rio Pardo de } \\
\text { Minas -MG }\end{array}$ & Camponês \\
\hline & L27 & Zumba e funcional & Tapira-MG & Urbano \\
\hline & L28 & Estaquia de plantas & $\begin{array}{l}\text { Fazenda Santo } \\
\text { Antônio do } \\
\text { Roçado - } \\
\text { Comunidade } \\
\text { Canabrava - } \\
\text { Bonfinópolis de } \\
\text { Minas -MG }\end{array}$ & Camponês \\
\hline & L29 & Fabricação de calçados & Franca-MG & Urbano \\
\hline & L30 & $\begin{array}{c}\text { Produção Artesanal da } \\
\text { Rapadura }\end{array}$ & $\begin{array}{l}\text { Comunidade do } \\
\text { Tabocal } \\
\text { São Francisco - } \\
\text { MG }\end{array}$ & Camponês \\
\hline & L31 & Crochê & Ituiutaba-MG & Urbano \\
\hline & L32 & $\begin{array}{l}\text { Cultivo de mandioca } \\
\text { para produção de } \\
\text { farinha e goma. }\end{array}$ & $\begin{array}{l}\text { Comunidade } \\
\text { Vaqueta }\end{array}$ & Camponês \\
\hline
\end{tabular}

${ }^{2}$ Compõe o Centro Dandara localizado em São José dos Campos. Instituição criada e composta por mulheres para a promoção dos Direitos Humanos. 


\begin{tabular}{|c|c|c|c|}
\hline & & $\begin{array}{c}\text { São Francisco - } \\
\text { MG }\end{array}$ & \\
\hline L33 & Crochê & $\begin{array}{c}\text { Zona Rural - Rio } \\
\text { Pardo de Minas - } \\
\text { MG }\end{array}$ & Camponês \\
\hline L34 & Construção de cerca & $\begin{array}{c}\text { Fazenda Pari - } \\
\text { Berizal -MG }\end{array}$ & Camponês \\
\hline L35 & Produção leiteira & $\begin{array}{c}\text { Assentamento } \\
\text { Francisca Veras - } \\
\text { Campo Florido - } \\
\text { MG } \\
\end{array}$ & Camponês \\
\hline L36 & $\begin{array}{c}\text { Mesa Brasil - rede } \\
\text { nacional de bancos de } \\
\text { alimentos }\end{array}$ & $\begin{array}{l}\text { Zona Rural - } \\
\text { Areias- SP }\end{array}$ & Camponês \\
\hline L37 & Produção do café & $\begin{array}{c}\text { Zona Rural- Rio } \\
\text { Pardo de Minas - } \\
\text { MG }\end{array}$ & Camponês \\
\hline L38 & Produção de abóbora & $\begin{array}{c}\text { Zona Rural } \\
\text { Rio Pardo de } \\
\text { Minas -MG }\end{array}$ & Camponês \\
\hline L39 & $\begin{array}{l}\text { Fabricação da farinha } \\
\text { de mandioca }\end{array}$ & $\begin{array}{c}\text { Assentamento } \\
\text { Saco do Rio Preto } \\
\text { - Natalândia - MG }\end{array}$ & Camponês \\
\hline L40 & $\begin{array}{c}\text { Produção de salgados } \\
\text { - coxinha } \\
\end{array}$ & Uberaba-MG & Urbano \\
\hline L41 & $\begin{array}{c}\text { Infraestrutura, } \\
\text { construção de casas } \\
\text { comunitárias/barracões }\end{array}$ & $\begin{array}{l}\text { Comunidade } \\
\text { Alexandra } \\
\text { Kollontai - } \\
\text { Serrana -SP } \\
\end{array}$ & Camponês \\
\hline L42 & Farinha de Mandioca & $\begin{array}{l}\text { Comunidade } \\
\text { Aurora } \\
\text { Rio Pardo de } \\
\text { Minas -MG }\end{array}$ & Camponês \\
\hline L43 & Crochê & Viradouro-SP & Urbano \\
\hline L44 & Produção de leite & $\begin{array}{c}\text { Zona Rural- Dom } \\
\text { Bosco-MG }\end{array}$ & Camponês \\
\hline L45 & $\begin{array}{l}\text { Extração do pequi - } \\
\text { óleo de pequi }\end{array}$ & $\begin{array}{l}\text { Comunidade } \\
\text { Sobrado } \\
\text { Rio Pardo de } \\
\text { Minas -MG } \\
\end{array}$ & Camponês \\
\hline L46 & Crochê & Colômbia-SP & Urbano \\
\hline L47 & Costura & Uberaba-MG & Urbano \\
\hline L48 & Cultivo de mandioca & $\begin{array}{c}\text { Assentamento } \\
\text { Saco do Rio Preto } \\
\text { - Natalândia - MG }\end{array}$ & Camponês \\
\hline
\end{tabular}




\begin{tabular}{|c|c|c|c|}
\hline L49 & $\begin{array}{l}\text { Fabricação de doces } \\
\text { caseiros -Geléia de } \\
\text { Mocotó }\end{array}$ & $\begin{array}{c}\text { Campo Florido- } \\
\text { MG }\end{array}$ & Urbano \\
\hline L50 & Queijo artesanal & $\begin{array}{c}\text { Fazenda Atoleiro } \\
\text {-Zona Rural } \\
\text { Rio Pardo de } \\
\text { Minas-MG }\end{array}$ & Camponês \\
\hline L51 & Cultivo de mandioca & $\begin{array}{c}\text { Fazenda Furnas - } \\
\text { Zona Rural } \\
\text { Vargem Grande } \\
\text { do Rio Pardo-MG }\end{array}$ & Camponês \\
\hline L52 & $\begin{array}{c}\text { Produção de Polpa de } \\
\text { Frutas }\end{array}$ & $\begin{array}{l}\text { Comunidade } \\
\text { Sobrado } \\
\text { Rio Pardo de } \\
\text { Minas -MG } \\
\end{array}$ & Camponês \\
\hline
\end{tabular}

Fonte: Da autora (2021).

Como podemos observar, os alunos da LECampo/UFTM nas duas turmas da EJA supracitadas são, em sua grande maioria, oriundos de contextos do campo, perfazendo um total de $69 \%$, e encontram-se localizados principalmente nas regiões do Norte e Noroeste do Estado de Minas Gerais.

Outro aspecto bastante característico refere-se às práticas sociais que emergem de seus contextos, de modo geral, centrais para a cultura, identidade e subsistência das comunidades quando pensamos nos contextos campesinos. A exemplo do cultivo ou produção de derivados da mandioca, tais como: polvilho, farinha e goma, que aparecem nos trabalhos de 16 licenciandos, sendo bastante representativos no Norte de Minas Gerais. Também aparece como central nas produções artesanais a rapadura e a cachaça, derivadas do cultivo da cana-de-açúcar. Encontramos ainda outros cultivos como práticas sociais locais do campo tais como: feijão, café e abóbora, além de produções artesanais do campo e urbanos, tais como: doces, salgados, queijos, mudas de plantas por estaquia, óleo do pequi e polpa de frutas por extrativismo entre outros. No contexto urbano, a prática de confecção artesanal de crochê aparece em 4 atividades. Em um dos trabalhos, a prática do crochê emergiu também de uma licencianda oriunda do campo. Tal fato pode ser justificado por uma possível falta de identificação com a terra, ausência de uma identidade camponesa ou mesmo a dificuldade de enxergar o campo como local de produção de conhecimento. 
No ambiente urbano há uma riqueza de práticas sociais relacionadas ao trabalho, no entanto, acreditamos que haja uma certa dificuldade dos estudantes destes contextos em identificá-las. Tal dificuldade pode estar associada ao fato que, no ambiente urbano, o trabalho é visto como algo obrigatório, externo ao ser e existir. Já no campo as relações são mais conectadas, vida, existência e trabalho, especificamente quando se consideram os contextos da agricultura familiar. Assim, em contextos urbanos, as práticas sociais relacionadas ao trabalho passam a ser vistas como mais utilitárias, resultado muitas vezes de um trabalho alienado no qual o sujeito urbano não se identifica com ele. Algo similar ocorre com o trabalho rural, na lógica capitalista.

Em se tratando de alunos do primeiro período do curso, acreditamos que a emergência destas práticas sociais e não outras, seja reflexo de uma identificação mais imediata com seu local de moradia, uma vez que estamos cercados por práticas sociais, seja em contextos camponeses ou urbanos. Isso pode explicar, por exemplo, a opção de uma das licenciandas em trabalhar com as atividades físicas como a zumba e o funcional praticadas ao ar livre como resultado de políticas públicas municipais locais. Logo, pode-se entender que, quando não estou trabalhando, participo de uma prática social. O que demonstra a exterioridade em que o trabalho é visto enquanto prática social na sociedade capitalista.

É preciso considerar que o conceito de prática social, a partir da perspectiva teórica, outrora discutida neste artigo, começa a ser apropriado por estes estudantes não apenas na disciplina de EJA como em outras disciplinas do primeiro período na LECampo. Deste modo, trata-se de um conceito em construção. Nesse sentido, reconhecemos a dificuldade dos alunos em identificar uma prática social local, mesmo estando imersos em uma dezena delas. A dificuldade permanece quando são orientados a descrever a prática. Novamente a naturalização daquilo que é familiar, muitas vezes, os impede de acessar compreensões mais profundas dos processos e produtos contidos na prática escolhida.

Outro aspecto de extrema relevância na emergência destas práticas e não outras diz respeito à concepção de trabalho que exibem estes licenciandos, adicionando valor e status à prática 
escolhida e ainda mais aos sujeitos que a praticam. Em outras palavras, a prática de crochê pode ser vista por muitos como lazer, hobby, no entanto, para estes licenciandos, o crochê também é uma atividade, um trabalho realizado. Por fim, cabe destacar que o próprio percurso formativo destes licenciandos, mesmo que inicial, favorece a escolha de práticas mais comunitárias e carregadas identitariamente com os aspectos do campo.

\section{A identificação dos conhecimentos contidos nas práticas de trabalho}

Um grande desafio para os licenciandos do campo na disciplina da EJA, em particular, é o exercício de identificação dos conhecimentos presentes nas práticas sociais escolhidas por eles. Trata-se de um deslocamento necessário, um reconhecimento valorativo para aquilo que os cerca ao mesmo tempo que um esforço de relembrar a existência de conteúdos escolares aprendidos em outras etapas formativas de sua vida. De igual modo, estimulamos também, o exercício de reconhecimento e valorização de saberes da cultura local. Conhecimentos estes presentes no modo de fazer de cada uma das práticas, aprendidos ao longo das gerações, reproduzidos, validados e reformulados à luz de novos aprendizados.

Tem-se como característica desta etapa da atividade de PCC na disciplina EJA da LECampo uma profusão de conhecimentos matemáticos acerca dos conteúdos unidades de medida e operações com números naturais inteiros, em detrimento de quaisquer outros. Assim, seja qual for a prática social, um dos primeiros conhecimentos destacados pelos alunos são as possibilidades de medição, principalmente, utilizando-se de unidades consideradas não convencionais tais como o palmo, o passo e o pé. Também o cálculo utilizando unidades de medida convencionais como quilos, metros, litros etc.

De modo semelhante, Velho e De Lara (2011), ao pesquisarem os saberes matemáticos produzidos e/ou praticados por trabalhadores, observaram que esses mesmos saberes matemáticos eram mobilizados juntamente com o raciocínio lógico de sujeitos no trabalho como cozinheira, zeladora, costureira, marceneiro e 
construtor. As autoras destacam o fato que a matemática produzida e/ou utilizada por estes sujeitos está inerentemente relacionada à necessidade de resolução de situações-problema de seu cotidiano.

[...] o aluno adulto, devido ao seu histórico de
vivências, tanto pessoal como profissional, agrega
saberes práticos intrínsecos e necessários as suas
experiências diárias, os quais são importantes e
devem ser respeitados como tal. Portanto, na
escola, ao se defrontarem com conceitos
elaborados, esses saberes encontrariam a
oportunidade de serem aprofundados e
legitimados. A problemática encontra-se no resgate
e significação desses saberes (VELHO; DE LARA,
2011, p.9).

Esta discussão suscita a relevância da abordagem Etnomatemática nas salas de aula da EJA e abre possibilidades de aprofundamentos teóricos sobre a matemática enxergada pelos licenciandos do campo em suas práticas sociais.

"[...] a Etnomatemática, por ser desenvolvida no cotidiano, também se manifesta na cultura do trabalho, através da relação dos adultos com seus conhecimentos informais, saberes esses que se redefinem e se aprimoram na experiência diária", (VELHO; DE LARA (2011, p. 9-10).

Estimulados a olhar para outros conhecimentos presentes nas práticas sociais, os estudantes passam a identificar também os processos e maquinários, a exemplo de tecnologias como ralador, prensa, tachos, ou seja, instrumentos fundamentais em algumas práticas como na fabricação da goma, do polvilho ou da farinha de mandioca, na produção da rapadura ou da cachaça e na fabricação de doces. Os conhecimentos que envolvem as ciências naturais, tais como a Física, a Química e a Biologia, são pouco identificados. Para isso, é de extrema importância a mediação da professora da disciplina ao chamar o olhar do estudante para a riqueza e potencialidade de conhecimentos contidos na prática social escolhida. 
Por um lado, é possível que a dificuldade de reconhecimento dos conhecimentos científicos presentes nas práticas de trabalho do cotidiano seja um reflexo da sociedade que historicamente considera como ciência aquilo que está fora da produção popular, mas dentro do consumo deste. Exemplo: o chá caseiro feito de folhas de ervas presentes em casa não é considerado ciência, mas estas mesmas folhas processadas e disponíveis em uma caixinha na farmácia, compõe-se de um produto de status científico. Por outro lado, podemos questionar se as ciências, tal como estão no currículo escolar, fazem sentido na vida destes indivíduos.

Apesar de os letramentos matemático e científico, especificamente, terem avançado em grande medida para dialogar com o cotidiano dos alunos, especificamente através de movimentos como o CTSA (Ciência, Tecnologia, Sociedade e Ambiente), por exemplo, estes são apenas algumas das vertentes possíveis no que diz respeito ao ensino-aprendizagem em contextos de Educação de Jovens e Adultos. Defendemos que as práticas sociais em si sejam para os sujeitos da EJA pontos de articulação mais concretos com seu cotidiano e passíveis de discussão e diálogo com a matemática, com as ciências e com outras tantas áreas disciplinares.

As diferentes populações humanas apresentam um arsenal de conhecimentos sobre o ambiente que as cerca. Propriedades terapêuticas e medicinais de animais e plantas, a percepção dos fenômenos naturais, como as estações do ano, tempo para plantar e colher, classificação de animais e plantas, organização de calendários, dicionários, sazonalidade de animais e sua relação com aspectos da natureza são organizações que formam um cabedal de saberes que comumente são chamados de conhecimentos tradicionais (BASTOS, 2013, p.6195).

Os povos e comunidades do campo possuem uma diversidade epistemológica acerca do mundo, ou seja, diferentes formas de conhecer que não rivalizam nem competem com o conhecimento científico, mas os complementa por vezes (SANTOS, 2009; CREPALDE et al, 2019). Neste sentido, o reconhecimento dos 
conhecimentos tradicionais que envolvem a prática social dos futuros professores da LECampo é parte da atividade de PCC. Nela, os conhecimentos tradicionais ora aparecem em conjunto com os conhecimentos matemáticos e/ou científicos presentes na prática, ora isolados deles. $\mathrm{O}$ trecho a seguir, ilustra a matemática praticada conjuntamente com os conhecimentos tradicionais de agricultores familiares de um assentamento em São Francisco, Minas Gerais, no cultivo do feijão, prática social retratada por L23 em seu PCC:

O uso da matemática é muito presente em todo o processo de produção, desde calcular o tamanho da terra e a quantidade de semente que vai precisar [...] para esse cálculo é feito uma média assim: um quilo de feijão tem capacidade de produzir uma saca de sessenta quilos cheia de feijão, quando produz bem. Então tenho uma estimativa que se eu plantar cinco quilos de feijão posso colher até cinco sacas, depende claro do tempo e da variedade escolhida, uma vez que tudo é no sistema sequeiro (L23).

Aqui percebemos a estimativa dos agricultores quanto à colheita a ser realizada a partir de uma quantidade fixa de grãos semeados, desde que as condições ambientais para tal plantio estejam favoráveis. Já $L 7$, ao descrever a prática de produção artesanal de rapadura em uma comunidade do campo de Rio Pardo de Minas, deixa explícitos os vários momentos em que o conhecimento científico participa do processo juntamente com o conhecimento tradicional dos produtores da rapadura na comunidade.

[...] nos meses de outubro a dezembro é plantada a cana, conhecida na comunidade como "cana Java" que, com um ano, ela é cortada e moída no engenho. Antes eles usavam engenhos puxado por bois, mas com o passar do tempo eles começaram a usar o engenho tocado a energia elétrica, dizem eles que facilita mais o trabalho e conseguem moer mais cana no dia em menos tempo. Depois do processo de moagem a garapa é colocada num tacho de cobre [...] dizem eles que o cobre deixa a garapa mais clara, tendo em vista que o tacho de ferro deixa a garapa 
mais escura, além do cobre ser mais resistente ao fogo. E depois de colocada a garapa no tacho é posto na fornalha, colocando fogo na lenha, essa lenha é retirada da natureza assim quando ela tiver seca é posta para queimar na fornalha para aquecer o tacho. A garapa, quando começa a ferver, ela espuma. Aí, deve-se mexer a garapa com uma "espumadeira" feita de um cabo de madeira com uma cuia na ponta feita de cabaça que deve ser feito uns furos no fundo da cuia, para ficar subindo a garapa e escorrendo pelos furos na cuia, esse processo [...] ((é)) para não deixa a garapa derramar do tacho. Aos poucos vai se tornando mel com a fervura. [...]quando vai fervendo o mel, ele começa a espumar muito e deve ficar mexendo constantemente [...] com a espumadeira para que, assim, o mel diminua a sua espumação e não derrame. Trabalho nada fácil pois cansa muito ficar mexendo o mel, sem contar com o calor que faz perto da fornalha. Depois de, em média, umas quatro horas [...] se preferir colocar uma colher de chá de óleo de cozinha no mel [...] o Sr. "O" explica que é algo opcional, mas que aprendeu com seus pais e que apresenta bons resultados para agilizar esse processo, para que a espumação cesse para poder tira o mel do tacho. Feito tudo isso, deve-se colocar o mel numa gamela e mexer bastante com uma pá até ficar bem consistente [...] ((o mel)) mais grosso que já é a rapadura, que só precisa colocar nas formas de madeira e deixar esfriar e a rapadura estará pronta para o consumo (L7).

$\mathrm{Na}$ descrição de $\mathrm{L7}$, encontramos o processo artesanal de fabricação da rapadura no engenho que passa a contar com a energia elétrica. Também a propriedade do cobre, presente no tacho e sua relação com a coloração da garapa. Os processos termoquímicos presentes nas etapas de fervura e transformação da lenha, dente outros conhecimentos científicos. Também se observa a integração entre estes conhecimentos e os tradicionais, no uso da cuia de cabaça como escumadeira, na adição do óleo no melado, etc. Tratam-se de "[...] experiências ((que)) não só usam linguagens diferentes, mas 
também distintas categorias, diferentes universos simbólicos [...]" (SANTOS, 2009, p. 52).

$\mathrm{Na}$ intenção de possibilitar o exercício de identificar preocupações comuns e complementares nas práticas sociais entre os conhecimentos que os compõe, tradicionais, científicos e matemáticos, chegamos então às propostas dos estudantes visando pensar nas práticas sociais relacionadas ao trabalho no/do campo em contextos da sala de aula EJA para o campo.

A proposta: do trabalho no/do campo à EJA

Os licenciandos em Educação do Campo apresentaram uma diversidade de propostas para se discutir o trabalho na EJA, tanto no Ensino Fundamental II (E.F.II) quanto no Ensino Médio (E.M.). Alguns utilizando-se de propostas práticas como experiências de ciências em sala de aula, reprodução da atividade de PCC para que os alunos da EJA pudessem identificar os conhecimentos contidos numa dada prática social; discussão social e econômica de algumas práticas relacionadas ao trabalho; reconhecimento das figuras planas contidas nos modelos gráficos do crochê; produção de maquetes; dentre tantas outras. Cabe ressaltar que, a proposta deveria ser pensada a partir de um contexto na qual determinada prática social fosse central para os jovens e adultos trabalhadores e trabalhadoras da EJA. Ou seja, não caberia ao professor "ensinar uma prática social relacionada ao trabalho", mas ao reconhecê-la como identitária entre seus alunos, saber trabalhar a partir e com ela em sala de aula.

Nesta seção apresentaremos cinco destas propostas de aulas para a EJA (Quadro 3) partindo de práticas sociais locais do campo e os conhecimentos que elas propiciam em articulação com os conhecimentos matemáticos e científicos escolares. A escolha das cinco propostas dentre os 52 trabalhos finais da disciplina teve como critério: i) advir de uma prática social relacionada ao trabalho no/do campo; ii) articular de modo mais concreto o trabalho com os conteúdos de matemática e/ou ciências para alguma etapa da EJA (E.F. II ou E.M.) e iii) coerência teórico-metodológica com a aprendizagem do adulto. 
Quadro 3 - Amostra de propostas de aula para EJA desenvolvidas na disciplina EJA da LECampo/ UFTM ao longo dos semestres $2019.2 \mathrm{e}$ 2020.2 .

\begin{tabular}{|c|c|}
\hline $\begin{array}{c}\text { Licenciando(a) / } \\
\text { prática social }\end{array}$ & Proposta \\
\hline $\begin{array}{l}\mathrm{L7} \\
\text { Produção da } \\
\text { rapadura }\end{array}$ & $\begin{array}{l}\text { "Sendo futuro professor da EJA, usaria os conhecimentos que já } \\
\text { são } \\
\text { pelos próprios produtores de rapadura, os que já fazem parte } \\
\text { da sua rotina de trabalho e que eles nem imagina como é tão } \\
\text { presente esse conhecimento em suas vidas, em que efetuam } \\
\text { cálculos matemáticos sem ter sequer estudado em uma escola, } \\
\text { mas que sabem calcular, o espaço de uma rua de cana a outra, } \\
\text { a quantidade de cana a ser plantada em um hectare, a } \\
\text { quantidade de garapa que uma hectare pode produzir, a } \\
\text { quantidade de litros que é necessário para produzir uma } \\
\text { rapadura e o lucro que podem adquirir com sua produção. } \\
\text { Todos esses conhecimentos matemáticos que eles sabem sem } \\
\text { nunca ter estudado e simplesmente usam em benefício do seu } \\
\text { trabalho. Mas que poderá ser utilizado na sala de aula com eles, } \\
\text { assemelhando esses conhecimentos que já sabem com os que a } \\
\text { escola pode proporcionar, dando exemplos de atividades que } \\
\text { fazem parte da sua rotina de trabalho, como na produção de } \\
\text { rapadura, usando no mesmo contexto e dando novos } \\
\text { valores para eles irem resolvendo e mostrando a eles outras } \\
\text { fórmulas matemáticas que podem chega ao resultado que } \\
\text { desejam saber em sua produção, tendo assim uma aula que } \\
\text { faça sentido para eles, assim como Paulo Freire orienta aos } \\
\text { professores." }\end{array}$ \\
\hline $\begin{array}{l}\text { L13 Produção do } \\
\text { Polvilho }\end{array}$ & $\begin{array}{l}\text { "[...] tendo como auxílio a vivência dos alunos que trabalham } \\
\text { com a prática de produção do polvilho (goma), abordaria a } \\
\text { prática discutida [...] relacionando os conhecimentos científicos } \\
\text { (química, física e biologia) e matemáticos. Perguntando-os } \\
\text { sobre a execução do processo de produção do polvilho, também } \\
\text { optando por levarem a uma fábrica de polvilho (goma), depois } \\
\text { interligaria os saberes práticos existentes, com a matéria teórica } \\
\text { assim facilitando com as matérias e atividades propostas, e } \\
\text { ensinando-os com os seus próprios saberes práticos utilizados } \\
\text { no dia a dia, discutindo cada passo da pratica que aborda a } \\
\text { matemática e os saberes científicos. Usando todas as etapas da } \\
\text { produção de polvilho (goma), para a teoria, desde as } \\
\text { multiplicações, adições e divisões, que são saberes matemáticos } \\
\text { que através da produção de polvilho(goma), é facilmente } \\
\text { associado entre a prática e a teoria, que levarei o grupo a } \\
\text { reconhecer." }\end{array}$ \\
\hline
\end{tabular}




\begin{tabular}{|c|c|}
\hline $\begin{array}{c}\text { L14 } \\
\text { Produção de Café } \\
\text { Sombreado }\end{array}$ & $\begin{array}{l}\text { "Será trabalhado [...] a matéria de Medidas de Áreas: Perímetro } \\
\text { e Área, e Unidades de Medidas: Massa, Volume e Comprimento. } \\
\text { [...]Ao observar as chácaras de café, veremos que cada uma tem } \\
\text { uma forma, tem medidas e lados, assim como um começo e um } \\
\text { fim, a matemática está super integrada nesse contexto o que } \\
\text { nos leva a querer aprender mais em como organizar essas } \\
\text { medidas em nossa propriedade. Por esse motivo conheceremos } \\
\text { cálculos que vão nos ajudar a medir o tamanho de nossas } \\
\text { chácaras e a quantidade de plantas que temos dentro dela. O } \\
\text { Perímetro é a medida do comprimento de um contorno, ou seja, } \\
\text { usando essa medida poderemos calcular a o perímetro da } \\
\text { chácara de cada propriedade. Primeiramente estudaremos os } \\
\text { perímetros, aprenderemos a medir com uma fita métrica toda } \\
\text { a chácara, anotaremos todos os números encontrados, e } \\
\text { posteriormente faremos os cálculos usando como base a planta } \\
\text { da chácara que faremos usando os números das medições. E } \\
\text { logo após estudaremos a base curricular dos perímetros com } \\
\text { maior facilidade." }\end{array}$ \\
\hline \multirow[t]{2}{*}{$\begin{array}{c}\text { L28 } \\
\text { Produção de } \\
\text { Mudas por } \\
\text { estaquia }\end{array}$} & $\begin{array}{l}\text { "A minha aula seria direcionada para a turma do } 7^{\circ} \text { ano do } \\
\text { ensino médio da EJA. Primeiramente pediria para cada aluno } \\
\text { dizer um pouco sobre suas experiências com a prática de } \\
\text { estaquia. Se já fizeram? Com quais plantas? Se usaram algum } \\
\text { conhecimento tradicional, científico ou matemático? Com qual } \\
\text { objetivo se faz essa prática para eles? Seria uma forma de cada } \\
\text { um apresentar a sua cultura. Em seguida, perguntar para eles } \\
\text { se sabem como é que a planta faz para soltar os brotos. Depois } \\
\text { perguntar para eles como eles imaginam que elas obtêm os } \\
\text { nutrientes necessários para as plantas, esperar para ver se tem } \\
\text { a resposta deles. Assim logo em seguida, dar uma aula de } \\
\text { Biologia, explicando sobre a substância que a estaca da planta } \\
\text { solta para ter os brotos, que é Auxina; Falar um pouco da } \\
\text { fisiologia das plantas; Mostrar como a planta faz a fotossíntese, } \\
\text { qual sua função e a importância. Seriam necessárias } 8 \text { aulas } \\
\text { teóricas. Em último lugar, partirímos para a aula prática, que } \\
\text { seria cada um fazer o preparo de uma estaquia em sua casa, } \\
\text { com qualquer planta que desse para a reprodução por estaquia, } \\
\text { de acordo com os seus costumes e os seus conhecimentos. De } \\
\text { acordo com o tempo ir passando, cada um teria que ir } \\
\text { registrando o desenvolvimento da planta e fazendo relatórios, } \\
\text { para que no dia que fosse marcado cada um apresentasse um } \\
\text { seminário apresentando o que observou e se teve mais algum } \\
\text { conhecimento que obteve com essa atividade." }\end{array}$ \\
\hline & $\begin{array}{l}\text { "Ao chegar na sala de aula do primeiro ano do ensino médio, } \\
\text { com alunos campesinos que para chegar a escola pegam }\end{array}$ \\
\hline
\end{tabular}



primeiro dia de aula de matemática, vou iniciar [...] me apresentando e falando que também já vivenciei a mesma trajetória que eles fazem hoje, para me tornar uma professora, e em seguida, conhecendo cada um por apresentações [...], vou Mandioca perguntar para cada discente seus conhecimentos matemáticos, e perguntando os mesmos se conhecem a cultura da mandioca, ao fim de cada resposta, informa-los que aprenderemos matemática através dos nossos conhecimentos diários, na forma de plantio espaçamentos de uma cova para outra, profundidade e afins, e também as medidas e o pesos da farinha ao final da produção. Sendo assim os cálculos matemáticos, medidas é pesos ficaram bem óbvios com as práticas diárias. Ao identificar as relações entre a matemática aprendida em sala de aula e suas atividades diárias no cultivo da mandioca, que fatores desde o cultivo até a produção de farinha que se relacionam com a matemática, vamos possibilitar nessa aula o pensamento crítico-reflexivo [...] em relação à importância da matemática na sua vida cotidiana, vamos nessa aula de hoje potencializar o processo ensinoaprendizagem da matemática, diminuindo as dificuldades e aumentando as possibilidades de vocês enquanto estudantes da EJA entender de medidas, espaçamentos é cálculos a partir do plantio da mandioca. Após cada estudante identificar a matemática, em suas praticar diária no cultivo da mandioca, cada um vai socializar com os demais para que os mesmos entendam como e comum o uso da matemática no nosso diaa-dia. Em seguida eles vão para suas casas e realizar na pratica o plantio de 4 ou 6 covas nos seus quintais para que os mesmos entendam onde está a matemática no plantio, e socializarão na próxima aula suas experiências na prática solicitada."

Fonte: Da autora (2021).

Importante ressaltar que estas propostas se referem às atividades de alunos de $1^{\circ}$ período do Curso de Licenciatura em Educação do Campo. No entanto, como podemos observar, apesar de ainda incipientes, sem um formato explicitamente pedagógico, estas propostas apresentam como exercício, a extremamente difícil tarefa de dialogar com os conhecimentos diversos emergentes de uma prática social com conhecimentos escolares. Se pensados do ponto de vista curricular, estas práticas mostram-se potenciais para ajudar aos alunos da EJA a entenderem-se como trabalhadores e trabalhadoras, uma vez que o trabalho "tem estado ausente na 
agenda pedagógica, apesar de ser uma experiência tão determinante no seu sobreviver desde a infância", destaca Arroyo (2017, p. 44).

Estas propostas assumem, como orientam Arroyo (2017), as experiências sociais e coletivas do mundo do trabalho como estruturantes pedagógicas, ou seja, a partir do trabalho e para o trabalho. Além disso, os conteúdos matemáticos e científicos passam a ser mais próximos dos trabalhadores e trabalhadoras EJA na medida em que incorporam a valorização daquilo que é praticado no cotidiano. Ao mesmo tempo, os conhecimentos escolares destas duas áreas do conhecimento (matemática e ciências) enriquecem-se quando dialogados com conhecimentos tradicionais, tornam-se mais reais e menos abstratos.

\section{CONSIDERAÇÕES FINAIS}

Formar professores para contextos de EJA no/do/para o campo implica reconhecer o trabalho como parte fundamental da relação social de todo ser humano. Assumir que o trabalho, em suas diferenças, são locais de produção de conhecimentos dos mais variados tipos. Identificar entre os trabalhadores e trabalhadoras que chegam às salas de aula da EJA no/do campo a quais trabalhos suas vidas estão vinculadas é central para se pensar e realizar uma educação emancipatória.

No contexto da disciplina de EJA da LECampo/UFTM, temos exercitado trazer o trabalho para o diálogo com as áreas dos conhecimentos do curso: Matemática e Ciências da Natureza. Primeiramente, num esforço de reconhecer e valorizar as práticas sociais relacionadas aos modos de viver e sobreviver dos povos do campo. Também como forma de investigar os conhecimentos que emergem destas práticas, e que podem ser postos em diálogo com a formação desses futuros professores no/do/para o campo. Por fim, como exercício de articulação na qual, ao se pensar nos sujeitos que chegam à EJA, pode-se dialogar com suas vivências.

As propostas que apresentamos neste artigo são apenas uma das formas de incorporar, valorizar e trabalhar as experiências dos trabalhadores e trabalhadoras, alunos e alunas da EJA. Partimos considerando o trabalho como uma prática social, sendo esta a 
centralidade destas experiências, ao mesmo tempo em que, reconhecemos os sujeitos como produtores de conhecimento e não meros reprodutores.

\section{REFERÊNCIAS}

ARROYO, M. G. Formar educadoras e educadores de jovens e adultos. In: SOARES, L. (Org.). Formação de educadores de jovens e adultos. Belo Horizonte, MG: Autêntica, 2006, p. 17-32.

ARROYO, M. G. Reinventando a EJA. Projeto de Educação de Trabalhadores-PET. In: NUNES, A.M.M.; CUNHA, C.M. (orgs). Projeto de Educação de Trabalhadores: pontos, vírgulas e reticências Um olhar de alguns elementos da EJA através do ensimesmo do PET. Belo Horizonte: PET, 2009.

ARROYO, M. G. O direito do trabalhador à educação. In: GOMEZ, C.M.; FRIGOTTO, G.; ARRUDA, M.; ARROYO, M.; NOSELLA, P. (Orgs.).

Trabalho e Conhecimento: dilemas na educação do trabalhador. São Paulo, SP: Editora Cortez, 2012, p. 103-125.

ARROYO, M. G. Outros sujeitos, Outras pedagogias. Petrópolis, RJ: Vozes, 2014.

ARROYO, M. G. Passageiros da noite: do trabalho para a EJA. Itinerários pelo direito a uma vida justa. Petrópolis, RJ: Vozes, 2017.

BASTOS, S.N.D. Etnociências na sala de aula: uma possibilidade para aprendizagem significativa. Anais. XI Congresso Nacional de Educação (EDUCERE), Curitiba, 23 a 26 de setembro, 2013.

BRASIL. Câmara dos Deputados. Programa "Com a palavra": Educação no Campo sofre com fechamento de escolas e elevada taxa de analfabetismo. Brasília: Rádio Câmara. [201-]. Disponível em: https://www.camara.leg.br/radio/programas/498211-educacao-nocampo-sofre-com-fechamento-de-escolas-e-elevada-taxa-deanalfabetismo/\#: :text=0\%20Brasil\%20possui\%20mais\%20de,\%3A \%20atinge\%20cerca\%20de\%2020\%25. Acesso em 13 jun. 2021.

CREPALDE, R. et al. A Integração de Saberes e as Marcas dos Conhecimentos Tradicionais: Reconhecer para Afirmar Trocas 
Interculturais no Ensino de Ciências. Revista Brasileira De Pesquisa Em Educação Em Ciências, 19, p. 275-297, 2019.

FERREIRA, G. A.; AUTOR, V. Título. Revista Brasileira de Educação do Campo, 2019.

FREITAS, K.P.; SILVA, L. H. Reflexão e análise da formação de educadores de jovens e adultos do campo. Educação \& Realidade, v. 41, N. 2, p. 555-573, 2016.

FRIGOTTO, G. Prefácio da $6^{\text {a }}$ edição. In: GOMEZ, C.M.; FRIGOTTO, G.; ARRUDA, M.; ARROYO, M.; NOSELLA, P. (Orgs.). Trabalho e

Conhecimento: dilemas na educação do trabalhador. São Paulo, SP: Editora Cortez, 2012a, p. 9-14.

FRIGOTTO, G. Trabalho, conhecimento, consciência e a educação do trabalhador: impasses teóricos e práticos. In: GOMEZ, C.M.; FRIGOTTO, G.; ARRUDA, M.; ARROYO, M.; NOSELLA, P. (Orgs.).

Trabalho e Conhecimento: dilemas na educação do trabalhador. São Paulo, SP: Editora Cortez, 2012b, p. 19-38.

INSTITUTO BRASILEIRO DE GEOGRAFIA E ESTATISTICA (IBGE). Pesquisa Nacional por Amostra de Domicílios Contínua Trimestral: População, por nível de instrução/2021. Disponível: https://sidra.ibge.gov.br/tabela/5919. Acesso em 13 jun. 2021. INSTITUTO NACIONAL DE ESTUDOS E PESQUISAS EDUCACIONAIS ANÍSIO TEIXEIRA (INEP). Censo Escolar, 2016. Brasília: MEC, 2017.

INSTITUTO NACIONAL DE ESTUDOS E PESQUISAS EDUCACIONAIS ANÍSIO TEIXEIRA (INEP). Censo Escolar, 2019. Brasília: MEC, 2020.

MOLINA, M.C.; ANTUNES-ROCHA, I. Educação do Campo: história, práticas e desafios no âmbito das políticas de formação de educadores-reflexões sobre o PRONERA e o PROCAMPO. Reflexão e Ação, v. 22, n. 2, p. 220-253, 2014.

OLIVEIRA, M.W. et al. Processos educativos em práticas sociais: reflexões teóricas e metodológicas sobre pesquisa educacional em espaços sociais. In: OLIVEIRA, M.W.; SOUSA, F.R. (Orgs). Processos educativos em práticas sociais: pesquisas em educação. São Carlos: EdUFSCar, 2014, p. 29-46. 
SILVA, L. H. As experiências de formação de jovens do campo:

alternância ou alternâncias. Curitiba: Editora CRV, 2012.

SANTOS, B. S. Para além do pensamento abissal: das linhas globais a uma ecologia de saberes. In: SOUSA SANTOS, B.; MENESES, M.P.

Epistemologias do Sul. Coimbra. Almeidina, 2009, p. 23-71.

UFTM. Universidade Federal do Triângulo Mineiro. Projeto

Pedagógico do Curso de Licenciatura em Educação do Campo.

Uberaba: UFTM, 2019.

VELHO, E.M.H.; DE LARA, I.C.M. O saber matemático na vida cotidiana: um enfoque etnomatemático. Alexandria: Revista de Educação em Ciência e Tecnologia, 4, 2, p. 3-30, 2011.

\section{AGRADECIMENTOS}

Agradecemos a parceria do Prof. Dr. Fernando Luís Pereira Fernandes (DECMT/ICENE/UFTM), que ministrou a disciplina de Campos Numéricos na LECampo/UFTM, em 2019.2, na proposição interdisciplinar da PCC para os alunos daquela turma propiciando reflexões mais profundas sobre práticas possíveis no contexto da matemática para a EJA.

Submetido em: Junho/ 2021.

Aceito em: Junho/ 2021. 